\title{
Prompt and consistent improvement of coronary flow velocity reserve following successful recanalization of the coronary chronic total occlusion in patients with viable myocardium
}

Milan Dobric ${ }^{1,2^{*}}$ (D, Branko Beleslin ${ }^{1,2}$, Milorad Tesic ${ }^{1,2}$, Ana Djordjevic Dikic ${ }^{1,2}$, Sinisa Stojkovic ${ }^{1,2}$, Vojislav Giga ${ }^{1,2}$, Miloje Tomasevic ${ }^{1,3}$, Ivana Jovanovic ${ }^{1,2}$, Olga Petrovic ${ }^{1}$, Jelena Rakocevic ${ }^{4}$, Nikola Boskovic ${ }^{2}$, Dragana Sobic Saranovic ${ }^{1,2}$, Goran Stankovic ${ }^{1,2}$, Vladan Vukcevic ${ }^{1,2}$, Dejan Orlic ${ }^{1,2}$, Dragan Simic ${ }^{1,2}$, Milan A. Nedeljkovic ${ }^{1,2}$, Srdjan Aleksandric ${ }^{1,2}$, Stefan Juricic ${ }^{1}$ and Miodrag Ostojic ${ }^{2}$

\begin{abstract}
Background: Coronary chronic total occlusion (CTO) is characterized by the presence of collateral blood vessels which can provide additional blood supply to CTO-artery dependent myocardium. Successful CTO recanalization is followed by significant decrease in collateral donor artery blood flow and collateral derecruitment, but data on coronary hemodynamic changes in relation to myocardial function are limited. We assessed changes in coronary flow velocity reserve (CFVR) by echocardiography in collateral donor and recanalized artery following successful opening of coronary CTO.

Methods: Our study enrolled 31 patients ( $60 \pm 9$ years; 22 male) with CTO and viable myocardium by SPECT scheduled for percutaneous coronary intervention (PCI). Non-invasive CFVR was measured in collateral donor artery before $\mathrm{PCl}, 24 \mathrm{~h}$ and 6 months post- $\mathrm{PCl}$, and $24 \mathrm{~h}$ and 6 months in recanalized artery following successful $\mathrm{PCl}$ of CTO.

Results: Collateral donor artery showed significant increase in CFVR $24 \mathrm{~h}$ after CTO recanalization compared to pre$\mathrm{PCl}$ values ( $2.30 \pm 0.49$ vs. $2.71 \pm 0.45, p=0.005)$, which remained unchanged after 6 -months $(2.68 \pm 0.24)$. Baseline blood flow velocity of the collateral donor artery significantly decreased $24 \mathrm{~h}$ post- $\mathrm{PCl}$ compared to pre- $\mathrm{PCl}(0.28 \pm$ 0.06 vs. $0.24 \pm 0.04 \mathrm{~m} / \mathrm{s}$ ), and remained similar after 6 months, with no significant difference in maximum hyperemic blood flow velocity pre-PCl, $24 \mathrm{~h}$ and 6 months post-PCl. CFVR of the recanalized coronary artery $24 \mathrm{~h}$ post-PCl was $2.55 \pm 0.35$, and remained similar 6 months later $(2.62 \pm 0.26, p=N S)$.

(Continued on next page)
\end{abstract}

\footnotetext{
* Correspondence: iatros007@gmail.com

${ }^{1}$ Cardiology Clinic, Clinical Center of Serbia, 26 Visegradska Street, Belgrade 11000, Serbia

${ }^{2}$ Faculty of Medicine, University of Belgrade, 6 Dr Subotica Street, Belgrade 11000, Serbia

Full list of author information is available at the end of the article
}

(c) The Author(s). 2020 Open Access This article is licensed under a Creative Commons Attribution 4.0 International License, which permits use, sharing, adaptation, distribution and reproduction in any medium or format, as long as you give appropriate credit to the original author(s) and the source, provide a link to the Creative Commons licence, and indicate if changes were made. The images or other third party material in this article are included in the article's Creative Commons licence, unless indicated otherwise in a credit line to the material. If material is not included in the article's Creative Commons licence and your intended use is not permitted by statutory regulation or exceeds the permitted use, you will need to obtain permission directly from the copyright holder. To view a copy of this licence, visit http://creativecommons.org/licenses/by/4.0/. The Creative Commons Public Domain Dedication waiver (http://creativecommons.org/publicdomain/zero/1.0/) applies to the data made available in this article, unless otherwise stated in a credit line to the data. 
(Continued from previous page)

Conclusions: In patients with viable myocardium, prompt and significant CFVR increase in both recanalized and collateral donor artery, was observed within $24 \mathrm{~h}$ after successful recanalization of CTO artery, which maintained constant during the 6 months.

Trial registration: ClinicalTrials.gov (Number NCT04060615).

Keywords: Coronary chronic total occlusion, CTO, Recanalization, Coronary flow velocity reserve, CFVR

\section{Introduction}

Coronary chronic total occlusion (CTO) is defined as the complete occlusion of coronary artery with no epicardial blood flow in the occluded arterial segment, lasting more than three months [1-4]. It is characterized by the presence of more or less developed collateral blood vessels, and variable amount of viable myocardium in the perfusion territory of occluded artery [5, 6]. Although collateral blood vessels can adequately supply CTO artery-dependent myocardium in order to maintain its viability, or even contractility at rest, collaterals are often insufficient to supply blood during exercise [7].

After successful opening of CTO, coronary circulation undergoes early changes with reduction in collateral flow [8], reflected also by an increase in fractional flow reserve in collateral donor artery due to reduced perfusion territory [9]. Still, the data on changes in microvascular dysfunction reflected by coronary flow velocity reserve (CFVR), both in occluded and collateral donor artery are scarce [10]. In particular, Werner et al. [11] have shown that about $50 \%$ of patients after successful CTO opening still have microvascular dysfunction defined as invasive CFVR $<2.0$, which improved over time in additional $50 \%$ of them. Improvement of CFVR over time was related to certain extent with improvement of wall motion score index, but not global ejection fraction. In general, the relation between microvascular dysfunction and myocardial function was not investigated in details, which is in contradiction with a need to define best patients who will gain most from the recanalization of CTO.

Noninvasive CFVR measured by 2D echocardiography represents versatile and highly reproducible noninvasive technique that may repeatedly interrogate coronary blood flow and microvascular dysfunction. Interestingly, this useful and user-friendly clinical noninvasive index was rarely used to assess hemodynamic and functional consequences following CTO opening [10]. In order to further define hemodynamic changes in coronary circulation, and relation to myocardial function, the aim of our study was to assess early and time-dependent changes in CFVR in occluded and non-occluded collateral donor artery after successful coronary CTO recanalization, in patients with viable myocardium in the territory of CTO as a prerequisite to perform PCI of CTO.

\section{Materials and methods Study population}

This was a prospective, observational study conducted at the Cardiology Clinic, Clinical Center of Serbia, which enrolled 31 patients (22 male; mean age $60 \pm 9$ years), with CTO of coronary artery (right coronary artery, RCA - 22 patients, left anterior descending coronary artery, LAD - 8 patients, and left circumflex artery, LCx 1 patient) scheduled for percutaneous recanalization. Inclusion criteria were: [1] age $\geq 18$ years old, [2] one CTO present on native coronary artery, with CTO defined as a complete occlusion of coronary artery with no epicardial blood flow in the occluded arterial segment, lasting more than three months with, [3] viable myocardium in the territory of chronically occluded artery with a presence of either (a) typical anginal symptoms, or (b) inducible ischemia in the territory of chronically occluded artery, and [4] epicardial vessel at the occlusion location estimated $\geq 2.5 \mathrm{~mm}$ in diameter. Presence of viability in the myocardium supplied by the occluded artery was considered as the most objective and quantitative evidence of myocardium at risk for CTO recanalization. Exclusion criteria were: [1] acute coronary syndrome during previous 30 days, [2] contraindication to dual antiplatelet therapy for 12 months, [3] contraindication to drug-eluting stent (DES) implantation, [4] presence of more than one CTO on native coronary arteries, [5] presence of left ventricle wall aneurysm, [6] previous myocardial infarction in the territory of non-CTO coronary artery, [7] significant stenosis (more than 70\% diameter stenosis) of non-CTO coronary artery requiring PCI [7]; previous coronary artery bypass graft surgery (CABG) or other cardiac surgical procedure, [8] left ventricle ejection fraction (LVEF) $<30 \%$, [9] permanent atrial fibrillation, [10] pregnancy, [11] serum creatinine $>180 \mu \mathrm{mol} / \mathrm{L}(2 \mathrm{mg} / \mathrm{dL}),[12]$ patients unable/unwilling to cooperate and attend clinical visits during the followup period. All the procedures were in accordance with the "Declaration of Helsinki" and the ethical standards of the Ethical committee of Faculty of Medicine, University of Belgrade. Informed consent was obtained from each patient. 


\section{Diagnostic evaluation before $\mathrm{PCl}$}

Before scheduled PCI for CTO, we have performed comprehensive functional evaluation to confirm a need for CTO opening. Thus, in all patients we have performed 2D transthoracic echocardiography, stress echocardiography for detection of myocardial ischemia, and single photon emission tomography myocardial perfusion imaging (SPECT MPI) for the detection of viable myocardium. In addition, for the purpose of the present study we have performed noninvasive transthoracic Doppler echocardiography to assess CFVR of the collateral donor artery (LAD or RCA) before PCI, as well as after PCI in both occluded and collateral donor arteries. In addition, to confirm net clinical benefit after CTO opening patients underwent quality of life evaluation using Seattle Angina Questionnaire (SAQ).

Initial $2 \mathrm{D}$ transthoracic echocardiography was used to evaluate regional left ventricular function. Wall motion score index (WMSI) was calculated using 17-segment model, with segmental kinetic grading score: 1 - normokinesia, 2 - hypokinesia, 3 - akinesia, and 4 - dyskinesia. WMSI was calculated by dividing the sum of the wall motion scores of each segment by total number of visualized segments [12]. Stress echocardiography exercise test was performed according to the submaximal Bruce treadmill protocol. Test was considered positive in the presence of exercise-induced wall motion abnormalities consistent with myocardial region supplied by occluded artery. Heart rate recovery was defined as a difference between maximum achieved heart rate during the test and heart rate after 1 min of recovery [13].

Noninvasive transthoracic Doppler echocardiography for the assessment of CFVR of the occluded and collateral donor artery was performed at rest and after the induction of hyperemia by intravenous infusion of adenosine $(0.140 \mathrm{mg} / \mathrm{kg} / \mathrm{min})$. CFVR was calculated as a ratio of maximum hyperemic and maximum baseline blood flow velocities [14]. The intake of xanthinecontaining foods or beverages was discontinued the day before the examination.

Gated SPECT MIBI was performed in all patients before PCI attempt using $466 \pm 49 \mathrm{MBq}$ (median $466 \mathrm{MBq}$ ) (range $407-555 \mathrm{MBq}, \quad 95 \%$ CI $450.1-483.5 \mathrm{MBq}$ ) of technetium-99 m-methoxyisobutylisonitrile $\quad\left({ }^{99 \mathrm{~m}} \mathrm{Tc}-\right.$ MIBI) intravenously, $10-15 \mathrm{~min}$ after giving $0.5 \mathrm{mg}$ of sublingual nitroglycerine [15]. The SPECT acquisition was performed 45-60 min after the injection, using single head SPECT camera (Siemens ecam, Hoffman Estates, Illinois, USA) in 64 projections over a $180^{\circ}$ semicircular arc extending from $45^{\circ}$ right anterior oblique position to $45^{\circ}$ left posterior oblique position. Size and the extent of perfusion defect were calculated based on 17-segment model, according to the European Association of Nuclear Medicine, European Society of
Cardiology guidelines for radionuclide imaging of cardiac function using 4D-MSPECT software $[15,16]$. Total score of MIBI uptake, Summed Rest Score (SRS), was calculated. Perfusion defect was expressed according to the territory of three major coronary blood vessels: LAD, RCA, and LCx. Myocardium was considered viable if MIBI uptake was $\geq 55 \%$ of the normal perfusion, with preserved wall thickening $[15,17]$. We also evaluated left ventricular ejection fraction using 4D-MSPECT automated algorithm for the determination of left ventricle surfaces from gated SPECT MPI [18].

SAQ is sensitive, valid and reproducible instrument used to assess the quality of life in patients with coronary artery disease [19]. This questionnaire is based on five different domains with scales reflecting patient's physical limitation, angina stability, angina frequency, treatment satisfaction, and quality of life. Each scale is transformed into score (0-100), where higher score values indicate better results and better function. SAQ was assessed before PCI of CTO, and 6 months after the CTO recanalization.

\section{Percutaneous coronary intervention $(\mathrm{PCl})$}

In all patients we utilized dual arterial access in order to optimally visualize the occluded artery and collateral blood vessels, and to plan the procedure. At the beginning of the procedure we applied nitroglycerine intracoronary $(200 \mu \mathrm{g})$ and intravenous heparin $(100 \mathrm{IU} / \mathrm{kg})$. PCI for CTO was initially attempted using antegrade approach, which was immediately switched to retrograde in case of anterograde failure, using standard devices and approaches for these types of interventions [5, 11]. After successful passage of the coronary wire and balloon pre-dilatation, PCI with implantation of coronary drug eluting stents was performed. Successful procedure was defined as a restoration of TIMI 3 flow in previously occluded artery with residual stenosis $<30 \%$ after drug eluting stent implantation.

\section{Examinations after $\mathrm{PCl}$}

After $24 \mathrm{~h}$ following successful PCI, noninvasive transthoracic Doppler echocardiography with CFVR measurements for both LAD and RCA was performed. CFVR measurement in LAD artery was feasible in all patients (100\%), whereas Doppler signal in RCA flow was of suboptimal quality in 2 patients, not allowing calculation of CFVR (feasibility 93\%). Six months after the intervention, we have repeated non-invasive CFVR measurement for both LAD and RCA, and SAQ. All patients had regular clinical visits (at 1, 6, and 12 months), and follow-up for the appearance of major adverse cardiovascular events (MACE: sudden cardiac death, nonfatal myocardial infarction, and repeated revascularization). 


\section{Statistical analysis}

Sample size was calculated using the formula for paired sample Student's t-test, based on the previously published studies and the study power of 0.8 to detect expected increase in CFVR in collateral donor artery after recanalization of CTO of $0.5[10,20,21]$, with the statistical significance level of 0.05 , and expected standard deviation for noninvasive Doppler CFVR in reference artery of 0.85 [22]. Calculated sample size was 23. With the current success rate of CTO recanalization at Cardiology Clinic, Clinical Center of Serbia of approximately $90 \%$, as well as the expected 6-month follow-up dropout of $15 \%$ of patients, optimal sample size was calculated to be 30 patients. Continuous variables are expressed as mean \pm standard deviation, or median and interquartile range (IQR), where appropriate. Categorical variables are expressed as frequencies and percentages. Differences between the groups were tested using chisquare test, paired sample Student's t-test, independent sample t-test, and repeated measures ANOVA where appropriate. Association between variables was tested using Pearson's correlation. Statistical analyses were performed using IBM SPSS Statistics version 25 for Windows (IBM Corporation, Armonk, NY, USA).

\section{Results}

Patients' baseline and angiographic characteristics are summarized in Table 1. Fourteen (45.2\%) patients had previous myocardial infarction, while stress echocardiography test was positive for inducible myocardial ischemia in 21 (67.7\%) patients, and negative in 10 (32.3\%) patients.

The majority of patients had chronically occluded RCA (22 patients, 71.0\%), 8 (25.8\%) patients had CTO of the LAD, while only one patient (3.2\%) had CTO of the LCx. Collateral-donor artery was LAD in $23(74.2 \%)$ patients, and RCA in $8(25.8 \%)$ patients. Single-vessel disease was present in the majority of patients (23 patients, 74.2\%). Six (19.4\%) patients had two-vessel disease, while $2(6.5 \%)$ patients had 3-vessel disease (lesions in nonoccluded coronary arteries were mild to moderate and not considered significant to perform PCI).

CTO recanalization procedure was successful in 28 (90.3\%) patients, and this was final study population involved in coronary physiology assessment defined by study protocol. Median number of implanted DES per patient was 2 (IQR 1-3). Median length of implanted stents was $51 \mathrm{~mm}$ (IQR $31.75-74.5 \mathrm{~mm}$ ), and median stent diameter was $3.0 \mathrm{~mm}$ (IQR $3.0-3.5 \mathrm{~mm}$ ).

\section{SPECT and stress echocardiography data}

Patients' SPECT and echocardiography data are shown in Table 2. SPECT MPI showed the presence of viable myocardium in all patients. Mean LVEF measured by
Table 1 Patients' baseline and angiographic characteristics ( $N=$ 31 patients, whole study group)

\begin{tabular}{ll}
\hline Baseline characteristics & \\
\hline Age, years (mean \pm SD) & $60 \pm 9$ \\
Male, n (\%) & $22(71)$ \\
BMI, kg/m² (mean \pm SD) & $27.6 \pm 3.8$ \\
Hypertension, n (\%) & $27(87.1)$ \\
Hyperlipidemia, n (\%) & $29(93.5)$ \\
Diabetes mellitus & $9(29.0)$ \\
Smoking & $19(61.3)$ \\
Family history of cardiovascular disease, n (\%) & $16(51.6)$ \\
Previous myocardial infarction, n (\%) & $14(45.2)$ \\
Previous PCl, n (\%) & $10(32.3)$ \\
Stress echocardiography test & \\
$\quad$ Positive, n (\%) & $21(67.7)$ \\
$\quad$ N Negative, n (\%) & $10(32.3)$ \\
Acetylsalicylic acid, n (\%) & $31(100)$ \\
P2Y12 inhibitor, n (\%) & $31(100)$ \\
ACE inhibitors, n (\%) & $20(64.5)$ \\
ARBs, n (\%) & $1(3.2)$ \\
Beta blockers, n (\%) & $24(77.4)$ \\
Trimetazidine, n (\%) & $13(41.9)$ \\
Long-acting nitrates, n (\%) & $9(29.0)$ \\
CCBs, n (\%) & $9(29.0)$ \\
Dtatins, n (\%) & $25(80.6)$ \\
\hline Siuretics, n (\%) & $7(22.6)$ \\
\hline
\end{tabular}

$S D$ standard deviation, $B M I$ body mass index, $P C l$ percutaneous coronary intervention, $A C E$ angiotensin converting enzyme, $A R B$ angiotensin II receptor blockers, $C C B$ calcium channel blockers

gated SPECT MPI was $57 \pm 10 \%$. Stress echocardiography test was positive in $18(64.3 \%)$ patients. Median number of visualized ischemic segments during the test was 2. Chest pain was recorded during the test in 7 (25\%) patients.

\section{CFVR of the collateral donor artery}

Pre-procedural noninvasive transthoracic Doppler CFVR of the collateral donor artery was $2.30 \pm 0.49$, which increased to $2.71 \pm 0.4524 \mathrm{~h}$ after the recanalization of CTO (Table 3). There was no difference in pre-PCI CFVR values between patients where LAD or RCA was the collateral donor artery $(2.39 \pm 0.53$ vs. $2.08 \pm 0.28$, respectively, $p=0.780$ ), with no difference in CFVR after $24 \mathrm{~h}(2.73 \pm 0.48$ vs. $2.64 \pm 0.35$, respectively, $\mathrm{p}=0.780)$. After 6 months, CFVR of the collateral donor artery was $2.68 \pm 0.24$, with no difference between LAD and RCA ( $2.70 \pm 0.25$ vs. $2.64 \pm 0.23$, respectively, $p=0.621$ ).

There was a significant difference in measured CFVR levels pre-PCI, $24 \mathrm{~h}$ after, and 6 months after $\mathrm{PCI}$ $(\mathrm{F}=392.181, \quad p<0.001) \quad($ Table 3, Fig. 1a). Post hoc 
Table 2 Patients' SPECT and echocardiography data $(n=28$ patients with successful CTO recanalization)

\begin{tabular}{ll}
\hline SPECT MPI & \\
\hline LVEF (mean \pm SD) & $57 \pm 10 \%$ \\
SRS (median, IQR) & $5(1-12)$ \\
Perfusion abnormality (median, IQR) & $8.5(1.5-19.5)$
\end{tabular}

Stress echocardiography

Test result

- Positive (n, \%)

$18(64.3 \%)$

- Negative

$10(35.7 \%)$

Ischemic myocardial segments (median, IQR) $2(0-3)$

Chest pain during the test $(n, \%)$

$7(25 \%)$

WMSI at rest

$1.139 \pm 0.166$

WMSI at peak stress

$1.301 \pm 0.275$

LVEF at rest (\%)

$55.9 \pm 9.7$

LVEF at peak stress (\%)

$53.1 \pm 11.1$

Heart rate recovery $(\mathrm{bpm}$, mean $\pm \mathrm{SD})$

$36.8 \pm 10.2$

Duke score (median, IQR)

$2.0(-1.5$ to 3.5$)$

LVEF left ventricle ejection fraction, $S D$ standard deviation, $S R S$ summed rest score, IQR interquartile range, WMSI wall motion score index, LVEF left ventricle ejection fraction, $b p m$ beats per minute

comparisons revealed significant increase in collateral donor artery CFVR $24 \mathrm{~h}$ after CTO recanalization as compared to pre-PCI values $(p=0.005)$, remaining at the same level during 6-months follow up ( $p=1.000$ for the 6-months vs. 24-h comparison).

We found significant difference in Doppler derived maximum baseline blood flow velocity of the collateral donor artery measured before PCI, 24h after, and 6 months after PCI (Table 3, Fig. 1b). Post hoc comparisons showed that there was significant decrease of Doppler derived maximum baseline blood flow velocity of the collateral donor artery measured $24 \mathrm{~h}$ after intervention, as compared to pre-PCI values $(p=0.011)$, and that this velocity remained similar during the 6-months follow-up ( $p=0.182$ for the 6-months vs. 24-h comparison). There was no difference in maximum hyperemic blood flow velocity of the collateral donor artery measured before PCI, $24 \mathrm{~h}$ after, and 6 months after PCI ( $\mathrm{F}=2.007, p=0.148$ ) (Table 3, Fig. 1c).

As opposed to most, three patients demonstrated marked decrease in CFVR of the collateral donor artery $24 \mathrm{~h}$ after the procedure compared to prePCI values (from baseline 3.38 to 2.28 , from 3.68 to 2.92, and from 3.43 to 2.68 ; Fig. 1a). In two patients observed decline was largely driven by the decrease in maximum hyperemic blood flow velocity (from 0.81 to $0.58 \mathrm{~m} / \mathrm{s}$, and from 0.70 to $0.41 \mathrm{~m} / \mathrm{s}$ ). In third patient both baseline and hyperemic velocities increased (from 0.23 to $0.35 \mathrm{~m} /$ $\mathrm{s}$, and from 0.79 to $0.84 \mathrm{~m} / \mathrm{s}$, respectively). Analyzing clinical, angiographic, and procedural characteristics, we could not find the possible explanation for the observed CFVR decrease in collateral donor artery.

Change (delta) in CFVR of the collateral donor artery $24 \mathrm{~h}$ post-PCI compared to pre-PCI values showed inverse correlation with LVEF measured by gated SPECT MPI ( $r=-0.523, p=0.007$, Fig. 2), but showed no correlation with WMSI on transthoracic echocardiography $(p=0.405)$, nor correlation with patients' initial stress echocardiography test result $(p=0.120)$, gender $(p=$ $0.782)$, smoking status $(p=0.487)$, presence of dyslipidemia $(p=0.893)$, diabetes $(p=0.839)$, or previous myocardial infarction $(p=0.858)$. We further investigated the relation of stress-test induced changes in left ventricular function to hemodynamic changes induced by CTO recanalization. We correlated changes (delta) in LVEF and WMSI during stress echo test (baseline minus peak stress values) to non-invasive hemodynamic parameters in collateral donor and CTO arteries, and found that only maximum hyperemic blood flow achieved in CTO artery $24 \mathrm{~h}$ after recanalization was related to change (decrease) in $\operatorname{LVEF}(\rho=0.413, p=0.029$, Table 4).

Table 3 Temporal changes in CFVR, maximum baseline blood flow, and maximum hyperemic blood flow in collateral donor artery and recanalized coronary artery ( $n=28$ patients with successful CTO recanalization)

\begin{tabular}{lll}
\hline & Collateral donor artery & Recanalized artery \\
\hline CFVR pre-PCl & $2.30 \pm 0.49$ & $/$ \\
• Maximum baseline blood flow velocity $(\mathrm{m} / \mathrm{s})$ & $0.28 \pm 0.06$ & $/$ \\
• Maximum hyperemic blood flow velocity $(\mathrm{m} / \mathrm{s})$ & $0.64 \pm 0.1$ & $/$ \\
CFVR $24 \mathrm{~h}$ after PCl & $2.71 \pm 0.45$ & $2.55 \pm 0.35$ \\
$\cdot$ Maximum baseline blood flow velocity $(\mathrm{m} / \mathrm{s})$ & $0.24 \pm 0.04$ & $0.28 \pm 0.07$ \\
• Maximum hyperemic blood flow velocity $(\mathrm{m} / \mathrm{s})$ & $0.64 \pm 0.16$ & $0.71 \pm 0.18$ \\
CFVR 6 months after PCl & $2.68 \pm 0.24$ & $2.62 \pm 0.26$ \\
$\cdot$ Maximum baseline blood flow velocity $(\mathrm{m} / \mathrm{s})$ & $0.26 \pm 0.05$ & $0.26 \pm 0.03$ \\
• Maximum hyperemic blood flow velocity $(\mathrm{m} / \mathrm{s})$ & $0.70 \pm 0.16$ & $0.69 \pm 0.09$ \\
\hline
\end{tabular}



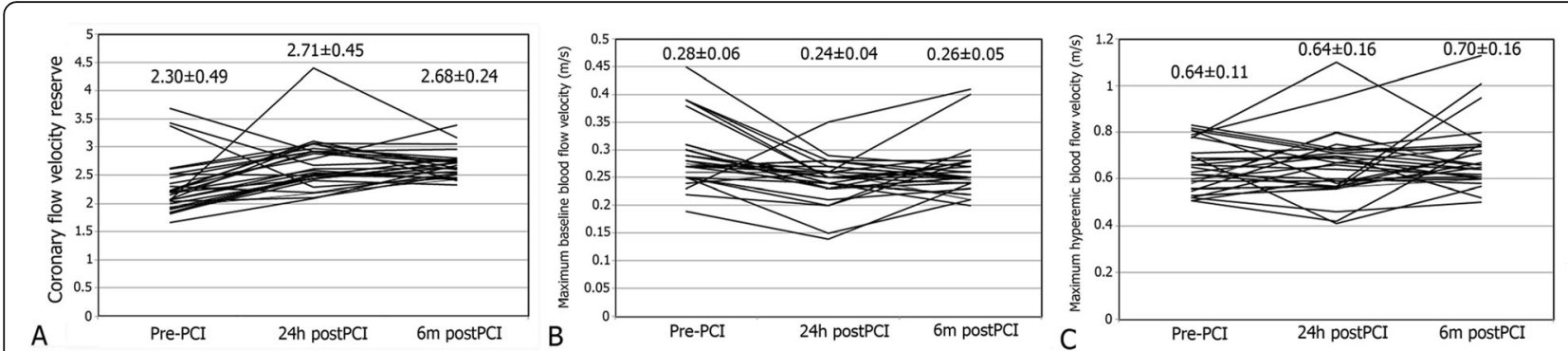

Fig. 1 Temporal change in CFVR (a), maximum baseline blood flow velocity (b), and maximum hyperemic blood flow velocity of the donor artery (c) before $\mathrm{PCl}, 24 \mathrm{~h}$ after, and 6 months after $\mathrm{PCl}$, *values represent mean \pm standard deviation

Example of CFVR pattern in collateral donor artery before and after CTO recanalization along with the corresponding angiographic finding is presented on Fig. 3.

\section{CFVR of the recanalized coronary artery}

CFVR of the recanalized coronary artery $24 \mathrm{~h}$ after PCI was $2.55 \pm 0.35$, with no difference between LAD and RCA $(2.49 \pm 0.35$ vs. $2.69 \pm 0.32$, respectively, $p=0.188)$. After 6 months, CFVR of the recanalized artery was $2.62 \pm 0.26$, which was almost the same as $24 \mathrm{~h}$ after successful PCI (Table 3, $p=0.279$ ). Six months after PCI, patients in whom RCA was recanalized had higher CFVR than patients in whom LAD was opened $(2.84 \pm$ 0.31 vs. $2.54 \pm 0.18, p=0.003$ ).

CFVR values of the recanalized artery $24 \mathrm{~h}$ after the intervention showed no correlation with LVEF measured on SPECT $(p=0.332)$, WMSI on transthoracic echocardiography ( $p=0.343)$, nor ischemia during stress echocardiography test $(p=0.836)$. Interestingly, CFVR of the CTO artery measured $24 \mathrm{~h}$ after PCI was not related to other patients' characteristics (gender, smoking, hyperlipidemia, diabetes, and previous myocardial infarction).

\section{SAQ measurements and clinical follow-up}

Patients reported improvements in four out of five SAQ domains during the 6 month follow up, as compared to pre-PCI values, while the fifth domain (anginal stability scale) showed borderline significance (Table 5).

Neither change in CFVR nor change in maximum baseline blood flow velocity of the collateral donor artery (6 months vs. baseline) or recanalized CTO artery was correlated to numeric change (delta) in five SAQ domains.

During 1, 6, and 12-month clinical follow-up, none of the study patients experienced major adverse cardiovascular events.

\section{Discussion}

To the best of our knowledge, this is the first study to evaluate noninvasive CFVR by $2 \mathrm{D}$ echocardiography in

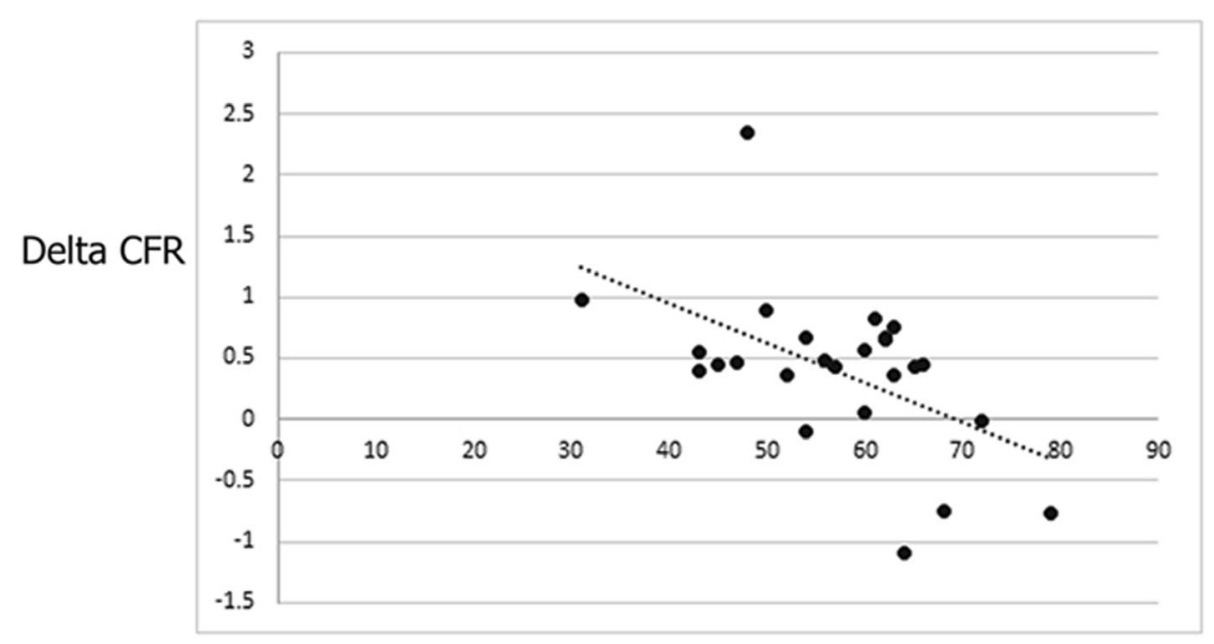

LVEF SPECT

Fig. 2 Inverse correlation between LVEF measured by gated SPECT MPI (x-axis) and change (delta) in CFVR of the collateral donor artery $24 \mathrm{~h}$ post-PCl compared to pre-PCl values (y-axis) 
Table 4 Correlation of changes in LVEF and WMSI during stress echo test and flow parameters in collateral donor and CTO arteries ( $n=28$ patients with successful CTO recanalization)

\begin{tabular}{|c|c|c|}
\hline & Delta LVEF (baseline minus peak stress) & Delta WMSI (baseline minus peak stress) \\
\hline \multicolumn{3}{|l|}{ Before $\mathrm{PCl}$ - collateral donor artery } \\
\hline CFVR & $\rho=0.214, p=0.275$ & $\rho=0.080, p=0.687$ \\
\hline Maximum baseline blood flow & $\rho=-0.162, p=0.409$ & $\rho=-0.251, p=0.197$ \\
\hline Maximum hyperemic blood flow & $\rho=0.232, p=0.236$ & $\rho=-0.098, p=0.619$ \\
\hline \multicolumn{3}{|l|}{ 24hafter $\mathrm{PCl}$ - collateral donor artery } \\
\hline CFVR & $\rho=-0.015, p=0.940$ & $\rho=-0.181, p=0.358$ \\
\hline Maximum baseline blood flow & $\rho=0.169, p=0.390$ & $\rho=0.082, p=0.680$ \\
\hline Maximum hyperemic blood flow & $\rho=-0.029, p=0.884$ & $\rho=0.204, p=0.298$ \\
\hline Delta CFVR donor artery (24 h vs. baseline) & $\rho=-0.214, p=0.274$ & $\rho=0.229, p=0.241$ \\
\hline \multicolumn{3}{|l|}{$24 \mathrm{~h}$ after $\mathrm{PCI}$ - СТО artery } \\
\hline CFVR & $\rho=0.318, p=0.099$ & $\rho=-0.028, p=0.887$ \\
\hline Maximum baseline blood flow & $\rho=0.302, p=0.119$ & $\rho=-0.376, p=0.059$ \\
\hline Maximum hyperemic blood flow & $\rho=0.413, p=0.029 *$ & $\rho=-0.155, p=0.431$ \\
\hline
\end{tabular}

$\mathrm{PCl}$ percutaneous coronary intervention, CFVR coronary flow velocity reserve; ${ }^{*} p<0.05$

both donor and recanalized artery, demonstrating early and rapid restoration of blood flow in recanalized artery with compensatory reduction in resting blood flow in collateral donor artery. In particular, our study demonstrated that in patients with viable myocardium undergoing PCI of CTO, successful recanalization of occluded artery induced prompt restoration of CFVR in recanalized artery and significant increase in CFVR of the collateral donor artery within $24 \mathrm{~h}$, which maintained consistent and constant after 6 months follow-up. Increase in CFVR in collateral donor artery was largely driven by the significant reduction in the maximum baseline blood flow velocity within $24 \mathrm{~h}$ after CTO recanalization compared to pre-PCI values, while the maximum hyperemic blood flow velocity measured pre-PCI, $24 \mathrm{~h}$ after PCI and 6 months after PCI remained similar. It is of particular interest to note that no interaction was observed between CFVR improvement and previous myocardial infarction or diabetes mellitus that might induce microvascular dysfunction and blunt the effect of CTO recanalization, outlining the importance of myocardial viability for CTO recanalization.

If the perfusion territory is largely supplied by the collateral flow from the donor artery, CTO recanalization and restoration of anterograde flow results in the prompt reduction or even cessation of collateral flow. This could lead to the reduction of blood flow in the donor artery as well, which could be reflected as a change in hemodynamic parameters of the donor artery (e.g. fractional flow reserve, FFR). Previous study showed that the collateral flow supplies approximately $50 \%$ of the anterograde flow restored after the CTO recanalization [23]. Several trials have observed the increase in FFR of the donor artery after the successful recanalization of chronically occluded artery, which in some cases altered the FFR values so that initial FFR values of $<0.8$ increased and became functionally insignificant, requiring no revascularization [8, 24-29].

Coronary flow reserve evaluation either by invasive or non-invasive means, reflects both epicardial and microvascular compartment of coronary circulation, and have excellent negative predictive potential, meaning that when CFVR is $>2$, or particularly $>2.5$, both epicardial and microvascular beds are functioning normally [30, 31]. However, invasive evaluation of CFVR is available and performed only in very sophisticated centers, and measurement per se might be quite demanding and less feasible in certain patients [32,33]. On the other hand, non-invasive measurement of coronary blood flow velocity with CFVR assessed by transthoracic Doppler echocardiography is feasible and quite reproducible [34]. Nevertheless, evaluation of CFVR is generally more feasible in the LAD (above 95\%) [35-37] as compared to the RCA, for which feasibility goes from $85 \%$ [35] to $90 \%$ [37]. Interestingly, there are just a few data on CFVR interrogation by non-invasive $2 \mathrm{D}$ echocardiography in CTO patients. Pizzuto et al. [38] explored with just a single CFVR measurement coronary flow of the collateral donor artery within 24-48 $\mathrm{h}$ of the diagnostic coronary angiography, and found that CFVR values showed positive correlation with the degree of angiographically visible collaterals and the number of diseased vessels. However, CFVR values were not measured after CTO recanalization. Baykan et al. [10] evaluated only changes in CFVR of the donor artery before and after CTO recanalization, and observed significant increase in CFVR of the donor artery 3 months after the CTO recanalization compared to pre-PCI and CFVR values measured 


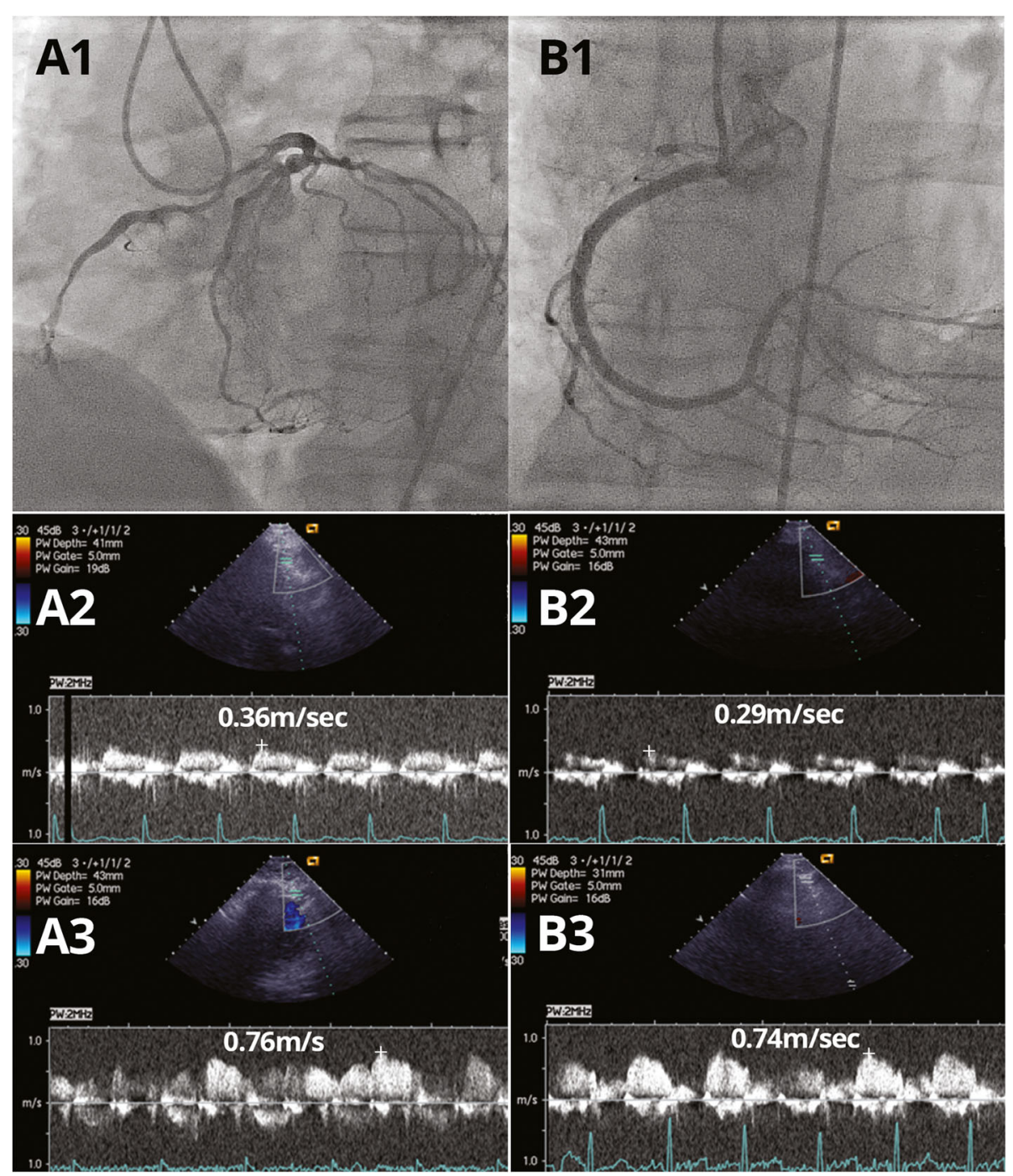

Fig. 3 a Before CTO RCA recanalization: CTO of RCA with collaterals from LAD (A1); peak baseline (A2) and hyperemic (A3) diastolic flow velocities in collateral donor LAD artery - CFVR LAD (0.76/0.36) - 2.11. b After CTO RCA recanalization: Recanalized RCA (B1); peak baseline (B2) and hyperemic (B3) diastolic flow velocities in LAD artery - CFVR LAD (0.74/0.29) - 2.55

Table 5 Values of SAQ domains 6 months after CTO recanalization vs. pre-PCI values $(n=28$ patients with successful CTO recanalization)

\begin{tabular}{llll}
\hline SAQ & Baseline & 6 months follow-up & $p$ \\
\hline Physical limitation & $68.31(51.86-79.87)$ & $85.49(53.39-90.97)$ & 0.019 \\
Angina stability & $50.00(0-50.00)$ & $50.00(31.25-50.00)$ & 0.051 \\
Angina frequency & $65(30-95)$ & $90(50-100)$ & 0.008 \\
Treatment satisfaction & $81.25(65.63-100.00)$ & $100.00(81.25-100.00)$ & 0.009 \\
Quality of life & $54.16(41.67-72.92)$ & $87.50(66.68-100.00)$ & 0.001 \\
\hline
\end{tabular}


$24 \mathrm{~h}$ post-PCI. In relation to our study, significantly lower values of CFVR were observed (almost in all patients under 2.0), which remained the same $24 \mathrm{~h}$ after PCI, but improved after 3 months. Our study showed significant increase in CFVR of the collateral donor artery as early as $24 \mathrm{~h}$ after CTO recanalization, which remained at the same level after 6 months compared to pre-PCI values. Different values and time changes in CFVR may be explained by the different population of patients including risk factors, previous myocardial infarction and other coronary stenosis in the donor artery.

Percutaneous treatment of coronary CTO represents one of the most challenging coronary lesions for operators, with several treatment algorithms among different CTO clubs [39], with the overall success rate in dedicated and expert centers of $>90 \%$. Recently, international collaboration resulted in a global consensus document emphasizing several principles for good clinical practice of CTO recanalization [40], with ischemic symptoms improvement as the primary indication for PCI of CTO. Therefore, careful selection of patients that could gain the most benefit from these complex interventions should rely on documentation of anginal symptoms, myocardial ischemia and/or viability in the CTO territory [11]. Here, we have demonstrated that in patients with objective evidence of viable myocardium by SPECT, even with previous myocardial infarction or without clear stress echocardiography evidence of myocardial ischemia, there is a prompt restoration of microvascular function as reflected by early improvement in CFVR. Recanalization of CTO translates into slight improvement of regional and global ejection fraction [41, 42], but in case of viable myocardium there is a high probability to achieve better functional outcome [41], here confirmed by a correlation between changes in CFVR and SPECT assessed myocardial function.

Successful CTO revascularization was proved to be associated with improved quality of life [43, 44], which was confirmed in our study. Our patients reported significant improvement of quality of life measured by SAQ 6 months after the CTO recanalization. As there was no relation between improvement of CFVR or other parameters and SAQ changes, we may only hypothesize that quality of life perception is more complex than mere improvement in coronary physiology or function.

CTO recanalization is demanding procedure that is known for large radiation exposure to the patient and the operator. Usually, for the purpose of detecting viability of the myocardium in the territory of occluded artery, additional cardiovascular imaging techniques employing ionizing radiation (such as SPECT) are utilized. Taking these radiation exposures together, cumulative dose to which patient is exposed could be significant. In our study population, estimates of radiation exposure during
SPECT were calculated from the 2015 International Commission on Radiological Protection Compendium for Tc-99 $\mathrm{m}$ with all doses then converted to an effective dose in $\mathrm{mSv}[45,46]$. Based on this information, we calculated patient radiation exposure of $0.009 \mathrm{mSv} / \mathrm{MBq}$ for Tc-99 m MIBI. For our group of patients mean radiation exposure was $4.1 \pm 0.4 \mathrm{mSv}$ (95\% CI $4.0-4.3 \mathrm{mSv}$; range 3.66-4.99 mSv, median $3.99 \mathrm{mSv})$. In comparison to radiation exposure during chest X-ray which is about 0.02 $\mathrm{mSv}$, this dose is equivalent to approximately 200 chest $\mathrm{X}$-rays [47]. Average radiation dose (total air-kerma) during PCI in our population was 1344 mGy (IQR 9672004 mGy).

Several study limitations are relevant to this study. First, we investigated highly selected group of patients with coronary CTO, viable myocardium in the territory of CTO, first attempt of CTO, and no-significant disease in the other coronary arteries, which may not adequately represent real-life clinical practice and all CTO lesions submitted for recanalization. Second, this was a singlecenter based study and it included relatively small number of participants. And finally, our study did not include control group of patients with CTOs treated conservatively. Finally, although non-invasive 2D echo CFVR is not utilized worldwide, our center has a large experience of CFVR measurements in different patients' subsets with high feasibility and reproducibility [14, 20, 48].

\section{Conclusions}

In patients with viable myocardium undergoing PCI of CTO, recanalization of CTO results in prompt and consistent restoration of coronary flow in recanalized coronary artery with rapid (within $24 \mathrm{~h}$ of PCI) improvement in coronary flow reserve of collateral donor artery, due to the reduction in maximum baseline blood flow velocity in donor artery and collateral derecruitment. Our results outline the importance of viability assessment in patients scheduled for PCI of CTO in order to gain most of recanalization of CTO.

\section{Abbreviations \\ CABG: Coronary artery bypass graft surgery; CFVR: Coronary flow velocity reserve; CTO: Chronic total occlusion; FFR: Fractional flow reserve; LAD: Left anterior descending coronary artery; LCX: Left circumflex artery; LVEF: Left ventricle ejection fraction; PCl: Percutaneous coronary intervention; RCA: Right coronary artery; SAQ: Seattle Angina Questionnaire; SPECT MPI: Single photon emission tomography myocardial perfusion imaging; WMSI: Wall motion score index}

Acknowledgements

Not applicable.

\section{Authors' contributions}

MD designed the study, was included in the acquisition and interpretation of the data, performed the $\mathrm{PCl}$ on CTO lesions and drafted the manuscript. $\mathrm{BB}$ designed the study, performed the $\mathrm{PCI}$ on CTO lesions and substantively revised the manuscript. MT was included in the acquisition the data, 
measured CFVR and performed the PCI on CTO lesions. ADjD was included in the acquisition the data, measured CFVR and performed stress echocardiography. SS was included in the acquisition the data and performed the $\mathrm{PCI}$ on CTO lesions. VG was included in the acquisition the data, measured CFVR and performed stress echocardiography. MT was included in the acquisition the data and performed the PCI on CTO lesions. IJ was included in the acquisition the data and performed2D transthoracic echocardiography. OP was included in the acquisition the data and performed2D transthoracic echocardiography. JR was included in the acquisition and interpretation of the data, and drafted the manuscript. NB was included in the acquisition the data and performed stress echocardiography. DSS was included in the acquisition the data and performed SPECT MPI. GS was included in the acquisition the data and performed the $\mathrm{PCl}$ on CTO lesions. W was included in the acquisition the data and performed the $\mathrm{PCI}$ on CTO lesions. DO was included in the acquisition the data and performed the PCI on CTO lesions. DS was included in the acquisition the data and performed the $\mathrm{PCI}$ on CTO lesions. MAN was included in the acquisition the data and performed the PCI on CTO lesions. SA was included in the acquisition the data and performed the PCl on CTO lesions. SJ was included in the acquisition the data and performed the $\mathrm{PCl}$ on CTO lesions. MO substantially contributed to the conception of this study. All authors have approved the submitted version. All authors have agreed both to be personally accountable for its own contributions and to ensure that questions related to the accuracy or integrity of any part of the work, even ones in which the author was not personally involved, are appropriately investigated, resolved, and the resolution documented in the literature.

\section{Funding}

This research was supported by Ministry of Education, Science and Technological Development of Republic of Serbia (grant numbers III41022 and 175018).

\section{Availability of data and materials}

The datasets used and/or analyzed during the current study are available from the corresponding author on reasonable request.

\section{Ethics approval and consent to participate}

All the procedures were in accordance with the "Declaration of Helsinki". This study was approved by the Ethical committee of Clinical Center of Serbia. Informed consent was obtained from each patient.

\section{Consent for publication}

Not applicable.

\section{Competing interests}

The authors declare that they have no competing interests.

\section{Author details}

${ }^{1}$ Cardiology Clinic, Clinical Center of Serbia, 26 Visegradska Street, Belgrade 11000, Serbia. ${ }^{2}$ Faculty of Medicine, University of Belgrade, 6 Dr Subotica Street, Belgrade 11000, Serbia. ${ }^{3}$ Department of Internal Medicine, Faculty of Medical Sciences, University of Kragujevac, 69 Svetozara Markovica Street, Kragujevac 34000, Serbia. ${ }^{4}$ Institute of Histology and Embryology, Faculty of Medicine, University of Belgrade, 6 Dr Subotica Street, Belgrade 11000, Serbia.

Received: 4 June 2020 Accepted: 16 July 2020

Published online: 21 July 2020

\section{References}

1. Sianos G, Werner GS, Galassi AR, Papafaklis MI, Escaned J, et al. EuroCTO Club. Recanalization of chronic total coronary occlusions: 2012 consensus document from the EuroCTO club. Eurolntervention. 2012;8:139-45.

2. Delacretaz E, Meier B. Therapeutic strategy with total coronary artery occlusions. Am J Cardiol. 1997;79:185-7.

3. Christofferson RD, Lehmann KG, Martin GV, Every N, Caldwell JH, et al. Effect of chronic total coronary occlusion on treatment strategy. Am J Cardiol. 2005;95:1088-91.

4. Werner GS, Gitt AK, Zeymer U, Juenger C, Towae F, et al. Chronic total coronary occlusions in patients with stable angina pectoris: impact on therapy and outcome in present day clinical practice. Clin Res Cardiol. 2009; 98:435-41.

5. Galassi AR, Werner GS, Boukhris M, Azzalini L, Mashayekhi K, et al. Percutaneous recanalization of chronic total occlusions: 2019 consensus document from the EuroCTO Club. Eurolntervention. 2019;15:198-208.

6. Werner GS. The role of coronary collaterals in chronic total occlusions. Curr Cardiol Rev. 2014;10:57-64.

7. Werner GS, Bahrmann P, Mutschke O, Emig U, Betge S, et al. Determinants of target vessel failure in chronic total coronary occlusions after stent implantation. The influence of collateral function and coronary hemodynamics. J Am Coll Cardiol. 2003;42:219-25.

8. Werner GS, Richartz BM, Gastmann O, Ferrari M, Figulla HR. Immediate changes of collateral function after successful recanalization of chronic total coronary occlusions. Circulation. 2000;102:2959-65.

9. Ladwiniec A, Cunnington MS, Rossington J, Mather AN, Alahmar A, et al. Collateral donor artery physiology and the influence of a chronic total occlusion on fractional flow reserve. Circ Cardiovasc Interv. 2015;8:e002219.

10. Baykan AO, Kalkan GY, Sahin DY, Elbasan Z, Gur M, et al. Coronary flow velocity reserve in donor artery and myocardial performance index after successful recanalization of chronic total coronary occlusions. J Invasive Cardiol. 2015;27:E75-81.

11. Werner GS, Emig U, Bahrmann P, Ferrari M, Figulla HR. Recovery of impaired microvascular function in collateral dependent myocardium after recanalization of a chronic total coronary occlusion. Heart. 2004;90:1303-9.

12. Lang RM, Bierig M, Devereux RB, Flachskampf FA, Foster $E$, et al. Recommendations for chamber quantification: a report from the American Society of Echocardiography's guidelines and standards committee and the chamber quantification writing group, developed in conjunction with the European Association of Echocardiography, a branch of the European Society of Cardiology. J Am Soc Echocardiogr. 2005;18:1440-63.

13. Cole CR, Foody JM, Blackstone EH, Lauer MS. Heart rate recovery after submaximal exercise testing as a predictor of mortality in a cardiovascularly healthy cohort. Ann Intern Med. 2000;132:552-5.

14. Giga V, Dobric M, Beleslin B, Sobic-Saranovic D, Tesic M, et al. Estimation of infarct size using transthoracic Doppler echocardiographic measurement of coronary flow reserve in infarct related and reference coronary artery. Int J Cardiol. 2013;168:169-75.

15. Pavlovic SV, Sobic-Saranovic DP, Beleslin BD, Ostojic MC, Nedeljkovic MA, et al. One-year follow-up of myocardial perfusion and function evaluated by gated SPECT MIBI in patients with earlier myocardial infarction and chronic total occlusion. Nucl Med Comm. 2009;30:68-75.

16. Verberne HJ, Acampa W, Anagnostopoulos C, Ballinger J, Bengel F, et al. European Association of Nuclear Medicine (EANM). EANM procedural guidelines for radionuclide myocardial perfusion imaging with SPECT and SPECT/CT: 2015 revision. Eur J Nucl Med Mol Imaging. 2015;42:1929-40.

17. Wahba FF, Bavelaar-Croon CD, Baur LH, Zwindermann AH, van Roosmalen $\mathrm{RP}$, et al. Detection of residual wall motion after sustained myocardial infarction by gated 99Tcm-tetrofosmin SPECT: a comparison with echocardiography. Nucl Med Comm. 2001;22:175-82.

18. Wolak A, Slomka PJ, Fish MB, Lorenzo S, Acampa W, et al. Quantitative myocardial-perfusion SPECT: comparison of three state-of-the-art software packages. J Nucl Cardiol. 2008;15:27-34.

19. Spertus JA, Winder JA, Dewhurst TA, Deyo RA, Prodzinski J, et al. Development and evaluation of the Seattle angina questionnaire: a new functional status measure for coronary artery disease. J Am Coll Cardiol. 1995;25:333-41.

20. Djordjevic-Dikic A, Beleslin B, Stepanovic J, Giga V, Tesic M, et al. Prediction of myocardial functional recovery by noninvasive evaluation of basal and hyperemic coronary flow in patients with previous myocardial infarction. J Am Soc Echocardiogr. 2011;24:573-81.

21. Beleslin B, Ostojic M, Djordjevic-Dikic A, Vukcevic V, Stojkovic S, et al. The value of fractional and coronary flow reserve in predicting myocardial recovery in patients with previous myocardial infarction. Eur Heart J. 2008; 29:2617-24.

22. Ladwiniec A, Cunnington MS, Rossington J, Thackray S, Alamgir F, et al. Microvascular dysfunction in the immediate aftermath of chronic total coronary occlusion recanalization. Catheter Cardiovasc Interv. 2016;87:1071-9.

23. Werner GS, Ferrari M, Heinke S, Kuethe F, Surber R, et al. Angiographic assessment of collateral connections in comparison with invasively determined collateral function in chronic coronary occlusions. Circulation. 2003;107:1972-7. 
24. Zimarino M, Ausiello A, Contegiacomo G, Riccardi I, Renda G, et al. Rapid decline of collateral circulation increases susceptibility to myocardial ischemia: the trade-off of successful percutaneous recanalization of chronic total occlusions. J Am Coll Cardiol. 2006:48:59-65.

25. Melikian N, Cuisset T, Hamilos M, De Bruyne B. Fractional flow reserve--the influence of the collateral circulation. Intern J Cardiol. 2009;132:e109-10.

26. Iqbal MB, Shah N, Khan M, Wallis W. Reduction in myocardial perfusion territory and its effect on the physiological severity of a coronary stenosis. Circ Cardiovasc Interv. 2010;3:89-90.

27. Kurisu S, Mitsuba N, Ishibashi K, Kato Y, Dohi Y, et al. A pitfall of fractional flow reserve associated with the presence of collateral circulation. Intern Med. 2011;50:2811-3.

28. Sachdeva R, Uretsky BF. The effect of CTO recanalization on FFR of the donor artery. Catheter Cardiovasc Interv. 2011;77:367-9.

29. Matsuo H, Kawase Y. Physiological impact of CTO recanalization assessed by coronary pressure measurement: a case report. Catheter Cardiovasc Interv. 2013;82:E459-64.

30. Cortigiani L, Rigo F, Gherardi S, Sicari R, Galderisi M, et al. Additional prognostic value of coronary flow reserve in diabetic and nondiabetic patients with negative dipyridamole stress echocardiography by wall motion criteria. J Am Coll Cardiol. 2007;50:1354-61.

31. Montisci R, Chen L, Ruscazio M, Colonna P, Cadeddu C, et al. Non-invasive coronary flow reserve is correlated with microvascular integrity and myocardial viability after primary angioplasty in acute myocardial infarction. Heart. 2006;92:1113-8

32. Everaars H, de Waard GA, Driessen RS, Danad I, van de Ven PM, et al. Doppler flow velocity and thermodilution to assess coronary flow reserve: a head-to-head comparison with $\left({ }^{15} \mathrm{O}\right) \mathrm{H}_{2} \mathrm{O}$ PET. JACC Cardiovasc Interv. 2018; 11:2044-54.

33. Gaster AL, Korsholm L, Thayssen P, Pedersen KE, Haghfelt TH. Reproducibility of intravascular ultrasound and intracoronary Doppler measurements. Catheter Cardiovascular Interv. 2004;53:449-58.

34. Ciampi Q, Zagatina A, Cortigiani L, Gaibazzi N, Borguezan Daros C, et al. Stress Echo 2020 study Group of the Italian Society of echocardiography and cardiovascular imaging. Functional, anatomical and prognostic correlates of coronary flow velocity reserve during stress echocardiography. J Am Coll Cardiol. 2019;74:2278-91.

35. Hyodo E, Hirata K, Hirose M, Sakanoue Y, Nishida Y, Arai K, et al. Detection of restenosis after percutaneous coronary intervention in three major coronary arteries by transthoracic Doppler echocardiography. J Am Soc Echocardiogr. 2010;23(5):553-9.

36. Tesic M, Djordjevic-Dikic A, Giga V, Stepanovic J, Dobric M, Jovanovic I, et al. Prognostic value of transthoracic Doppler echocardiography coronary flow velocity Reserve in Patients with nonculprit stenosis of intermediate severity early after primary percutaneous coronary intervention. J Am Soc Echocardiogr. 2018;31(8):880-7.

37. Jovanovic I, Tesic M, Giga V, Dobric M, Boskovic N, Vratonjic J, et al. Impairment of coronary flow velocity reserve and global longitudinal strain in women with cardiac syndrome $X$ and slow coronary flow. J Cardiol. 2020; 76(1):1-8.

38. Pizzuto F, Voci P, Puddu PE, Chiricolo G, Borzi M, Romeo F. Functional assessment of the collateral-dependent circulation in chronic total coronary occlusion using transthoracic Doppler ultrasound and venous adenosine infusion. Am J Cardiol. 2006;98:197-203.

39. Rinfret S, Harding SA. A new Japanese CTO algorithm: a step forward or backward? J Am Coll Cardiol. 2019;74:2405-9.

40. Brilakis ES, Mashayekhi K, Tsuchikane E, Abi Rafeh N, Alaswad K, et al. Guiding principles for chronic total occlusion percutaneous coronary intervention. Circulation. 2019;140:420-33.

41. Stuijfzand WJ, Biesbroek PS, Raijmakters PG, Driessen RS, Schumacher SP, et al. Effects of successful percutaneous coronary intervention of chronic total occlusion on myocardial perfusion and left ventricular function. Eurolntervention. 2017;13:345-54.

42. Megaly M, Saad M, Tajti P, Burke MN, Chavez I, et al. Meta-analysis of the impact of successful chronic total occlusion percutaneous coronary intervention on left ventricular systelicfuncion and reverse remodeling. J Interv Cardiol. 2018;31:562-71.

43. Wijeysundera $\mathrm{HC}$, Norris C, Fefer P, Galbraith PD, Knudtson ML, et al. Relationship between initial treatment strategy and quality of life in patients with coronary chronic total occlusions. Eurolntervention. 2014;9:1165-72.
44. Safley DM, Grantham JA, Hatch J, Jones PG, Spertus JA. Quality of life benefits of percutaneous coronary intervention for chronic occlusions. Catheter Cardiovasc Interv. 2014;84:629-34.

45. Mattsson S, Johansson L, Leide Svegborn S, Liniecki J, Noske D, Riklund KÅ, et al. Radiation dose to patients from radiopharmaceuticals: a compendium of current information related to frequently used substances. Ann ICRP. 2015:44(2 suppl):7-321.

46. Desiderio MC, Lundbye JB, Baker WL, Farrell MB, Jerome SD, Heller GV. Current status of patient radiation exposure of cardiac positron emission tomography and single-photon emission computed tomographic myocardial perfusion imaging. Circ Cardiovasc Imaging. 2018;11(12): e007565.

47. Picano E, Santoro G, Vano E. Sustainability in the cardiac cath lab. Int J Cardiovasc Imaging. 2007;23:143-7.

48. Djordjevic Dikic A, Tesic M, Boskovic N, Giga V, Stepanovic J, et al. Prognostic value of preserved coronary flow velocity reserve by noninvasive transthoracic Doppler echocardiography in patients with angiographically intermediate left main stenosis. J Am Soc Echocardiograph. 2019;32:74-80.

\section{Publisher's Note}

Springer Nature remains neutral with regard to jurisdictional claims in published maps and institutional affiliations.
Ready to submit your research? Choose BMC and benefit from:

- fast, convenient online submission

- thorough peer review by experienced researchers in your field

- rapid publication on acceptance

- support for research data, including large and complex data types

- gold Open Access which fosters wider collaboration and increased citations

- maximum visibility for your research: over $100 \mathrm{M}$ website views per year

At BMC, research is always in progress.

Learn more biomedcentral.com/submissions 